\title{
The role of macrobiota in structuring microbial communities along rocky shores
}

Rocky shore microbial diversity presents an excellent system to test for microbial habitat specificity or generality, enabling us to decipher how common macrobiota shape microbial community structure. At two coastal locations in the northeast Pacific Ocean, we show that microbial composition was significantly different between inert surfaces, the biogenic surfaces that included rocky shore animals and an alga, and the water column plankton. While all sampled entities had a core of common OTUs, rare OTUs drove differences among biotic and abiotic substrates. For the mussel Mytilus californianus, the shell surface harbored greater alpha diversity compared to internal tissues of the gill and siphon. Strikingly, a 7-year experimental removal of this mussel from tidepools did not significantly alter the microbial community structure of microbes associated with inert surfaces when compared with unmanipulated tidepools. However, bacterial taxa associated with nitrate reduction had greater relative abundance with mussels present, suggesting an impact of increased animal-derived nitrogen on a subset of microbial metabolism. Because the presence of mussels did not affect the structure and diversity of the microbial community on adjacent inert substrates, microbes in this rocky shore environment may be predominantly affected through direct physical association with macrobiota. 
2

3 The role of macrobiota in structuring microbial communities along rocky shores

4

5 Catherine A. Pfister ${ }^{*}$, Jack A. Gilbert ${ }^{1,2}$, Sean M. Gibbons ${ }^{2,3}$

$6 \quad{ }^{1}$ Department of Ecology and Evolution

7 and

$8 \quad{ }^{2}$ Institute of Genomic and Systems Biology

9 Argonne National Laboratory

10 Lemont, IL 60439 USA

$11{ }^{3}$ Biophysical Sciences Graduate Program

12 University of Chicago

13 Chicago IL 60637

14 *corresponding author: Department of Ecology \& Evolution, $1101 \mathrm{E} 57^{\text {th }} \mathrm{St}$, University of

15 Chicago, Chicago IL 60637, tele 773-834-0071, fax 773-702-9740, cpfister@uchicago.edu

16

17 Running title: rocky shore microbial community structure

18

19 Submitted to PeerJ

20

21

22

23

24 
INTRODUCTION

26 The dynamics and interactions of the macroscopic species on rocky shores of the northeast

27 Pacific Ocean have been well-characterized and thus have contributed significantly to our

28 understanding of coastal ecological processes (eg. Paine 1966; Wootton 1994; Estes and

29 Duggins, 1995). Although some specialized symbiotic associations have been described in rocky

30 shore species (Secord and Augustine, 2005; Bergschneider and Muller-Parker, 2008), we know

31 little about multi-taxa microbial associations. There is increasing evidence that many marine

32 macrobiota have surface biofilms (Grossart et al., 2005; Kvennefors et al., 2012) or

33 endosymbionts (Zurel et al., 2011; Wegner et al., 2012) or both (e.g. Qian et al., 2006; Taylor et

34 al., 2007). However, our understanding of the specificity of these associations and their

35 functional significance remain nascent with some notable exceptions (Webster and Taylor, 2012;

36 Fan et al., 2013; Heisterkamp et al., 2013). The shelf waters of the California Current Large

37 Marine Ecosystem (CCLME) maintain diverse and unique microbial communities across

38 upwelling areas (Bertagnolli et al., 2011). The relatively high productivity of this system has

39 been attributed to the seasonal upwelling of nitrate (Barber and Smith 1981), which can lead to

40 significant levels of carbon fixation. The diversity of potential plant and animal 'host' species in

41 the CCLME, their relatively large geographic range, their longevity and the provision of key

42 resources suggest they provide unique microniches capable of increasing the diversity and

43 function of microbial communities.

44 If macrobiota directly provide habitat for intertidal microbes (e.g. mussels, Pfister et al.,

45 2010; algae, Miranda et al., 2013) or indirectly provide resources such as nitrogen, in the form of

46 animal-regenerated ammonium, then our understanding of coastal biogeochemistry is incomplete

47 without considering the contribution of macrobiota. In the northeast Pacific, Tatoosh Island, WA 
48 shows persistent shoreward peaks of ammonium (Pfister et al., 2007), while the tidepools at

49 Second Beach, WA have animal-regenerated ammonium from the California mussel with locally

50 enhanced algal productivity, and microbial nitrification (Pfister 2007). We employed 16S rRNA

51 V4 amplicon sequencing to test whether microbes associated with macrobiota differ from those

52 in the water column and on inert surfaces. We further compared the identified microbial taxa

53 with those found when using shotgun metagenomics in a subset of samples for mussel shell

54 biofilms. Finally, we used a manipulative field experiment of mussel presence or absence in

55 tidepools to ask whether the increased rates of nitrogen remineralization and uptake

56 demonstrated with mussels by tracer ammonium addition (Pather et al., 2014) resulted in

57 changed bacterial communities on inert surfaces.

\section{MATERIALS AND METHODS}

59 We asked whether microbial diversity and abundance were distributed differentially among

60 intertidal microhabitats by 1) sampling distinct microhabitat types including artificial and natural

61 surfaces at Tatoosh Island $\left(48.32^{\circ} \mathrm{N}, 124.74^{\circ} \mathrm{W}\right)$, and 2). Sampling artificial and natural

62 substrates in the context of an animal removal experiment at nearby Second Beach $\left(48^{\circ}, 23^{\prime} \mathrm{N}\right.$,

$\left.63124,40^{\prime} \mathrm{W}\right)$. Tatoosh Island is $0.7 \mathrm{~km}$ off the northwestern tip of Washington State, USA and has

64 been well studied ecologically. Previous metagenomic analysis of biofilms associated with the

65 shells of mussels at Tatoosh Island demonstrated a rich microbial assemblage, with the genetic

66 capacity for nitrogen cycling (Pfister et al., 2010). On 6 Aug 2009, we sampled both inert and

67 biogenic substrates in situ, as well as artificial substrates. Biogenic substrates sampled included

68 the surface of the red alga Prionitis sternbergii $(\mathrm{n}=2)$, the anemone Anthopleura elegantissima

$69(\mathrm{n}=2)$, and gill tissue $(\mathrm{n}=3)$ and siphon tissue $(\mathrm{n}=1)$ of the California mussel Mytilus

70 californianus. These biogenic hosts were chosen because they are persistent members of the 
71 community and have relatively long-lived and sessile tissues that might provide a predictable

72 substrate. In addition to the biogenic surfaces, rocks were chipped off of bench adjacent to

73 mussel beds. Artificial substrates (glass crucible covers, $3 \mathrm{~cm}$ diam, www.leco.com) were

74 attached with epoxy on rock adjacent to mussel beds $(n=4)$ and in tidepools $(n=5)$ on 10 Jun

752009 and left in situ for 2 months. We chose glass crucible covers because they provided

76 heterogeneous surface, yet an inert substance. Immediately after a late morning collection at low

77 tide, samples were frozen and sent to $-80^{\circ} \mathrm{C}$ storage at the University of Chicago prior to

78 extraction. Environmental characteristics of the seawater, including nutrient concentrations,

79 were recorded as part of a regular sampling program (Wootton and Pfister, 2012) and are

80 reported in Table S1. The Upwelling Index for this latitude $\left(48^{\circ} \mathrm{N}\right)$ was, on average, positive

81 (www.pfeg.noaa.gov).

82 We tested whether the presence of mussels had entrained different microbial assemblages by

83 sampling natural and artificial substrates in tidepools where mussels had been removed or

84 unmanipulated since 2002 at Second Beach (Pfister, 2007), a north-facing complex of rocks 2

$85 \mathrm{~km}$ east of Neah Bay, WA, USA within the Makah Tribal Reservation. For seven years prior to

86 our microbial sample collection, mussels have been excluded from 6 tidepools that previously

87 contained mussels by pulling them out by hand at an approximately monthly interval during the

88 spring and summer months. Other tidepools that naturally had mussels served as controls. The

89 biogeochemistry of these experimental and control tidepools have been characterized multiple

90 times, allowing us to test for mussel effects on tidepool nutrient concentrations (nitrate, nitrite,

91 ammonium, and phosphorus), and seawater $\mathrm{pH}$ and oxygen and how it related to microbial

92 community structure. These parameters were measured 9 times in each tidepool during Aug 2009

93 and 12 times in Jul and Aug of 2010. We also estimated ammonium remineralization and 
94 removal rates with a tracer experiment with enriched ${ }^{15} \mathrm{NH}_{4}{ }^{+}$in 2010 (Pather et al., 2014). A

$952 \mathrm{~cm}^{2}$ piece of rock was chiseled from 5 pools with and 5 without mussels during morning hours

96 on 24 Aug 2009. We also sampled from glass cover slips that had incubated for 3 months in

97 these pools ( $\mathrm{n}=7$ controls, $\mathrm{n}=6$ mussel removal pools) with a copper paint barrier to exclude

98 molluscan grazers. To compare this benthic microbial assemblage to microbes in the water

99 column, we collected 3 plankton samples on $25 \mathrm{~mm} \mathrm{GF} / \mathrm{F}$ filters by pumping $300 \mathrm{~mL}$ of seawater

100 on an incoming tide (1100-1130h). Due to the 0.7 um pore size, we likely excluded many free-

101 living microbes, though high species richness still resulted (see below). All samples were frozen

102 and sent to storage at $-80^{\circ} \mathrm{C}$ at the University of Chicago prior to extraction.

103 For DNA extraction, we used the Power Soil DNA Extraction Kit (MoBio). The rock,

104 crucible cover substrates, and mussel shells were both swabbed with sterile cotton applicators

105 and brushed with sterile spiral dental brushes that were placed in the extraction solution.

106 Coverslips, filters, excised mussel gill or mussel siphon, anemones, and algae were placed into

107 the beadbeater vial and pulverized. Thus, our sampling of biogenic substrata included the

108 potential that microbes were part of the host tissue. The PCR amplification protocol followed

109 Caporaso et al. (2011) for multiplexing 16S rRNA samples. The PCR products were cleaned

110 with MoBio ${ }^{\mathrm{TM}}$ UltraClean htp PCR Clean-up kit. We amplified the V4 variable region of the

111 16S rRNA gene from community DNA using bar-coded primers according to Earth Microbiome

112 Project standard protocols (www.earthmicrobiome.org).

113

114 Sequence analysis

115 We used QIIME (v. 1.7.0, Quantitative Insights into Microbial Ecology; www.qiime.org) to

116 filter reads and determine OTUs as described in Caporaso et al. (2010a, 2011). Briefly, we used 
117 the open reference OTU picking workflow, where sequences were first clustered with the

118 Greengenes (Dec 2012) reference database (McDonald et al., 2012); we then allowed OTUs that

119 did not cluster with known taxa (at 97\% identity) in the database to cluster de novo. Singleton

120 and chloroplast-derived sequences were removed prior to downstream analyses. Representative

121 sequences for each OTU were aligned using PyNast, with a minimum alignment overlap of $75 \mathrm{bp}$

122 (Caporaso et al., 2010b). Alignments were used to build a phylogenetic tree (FastTree; Price, et

$123 a l ., 2009)$. We computed alpha diversity metrics among substrates using the alpha_diversity.py

124 script in QIIME (chao1, phylogenetic diversity and equitability), using the same sequence depth

125 for all samples (50000 sequences per sample). We used the beta_diversity_through_plots.py

126 script to compute beta diversity distances between samples (weighted UniFrac), and to construct

127 principal component (PCoA) plots, thus accounting for both the phylogenetic composition

128 (Lozupone et al., 2011) and the relative abundance of taxa. To test for significant sample

129 groupings based on these distance metrics, we employed PERMANOVA and PERMDISP using

130 the compare_categories.py script in QIIME. We tested whether the abundance of particular

131 OTUs differed significantly among different substrates using ANOVA analyses (Bonferonni

132 corrected) with the otu_category_significance.py script. OTU networks were constructed using

133 the make_otu_network.py script in QIIME. We further visualized the extent to which OTUs

134 were shared or unique among samples using Cytoscape network layouts (www.cytoscape.org).

135 Finally, we tested for patterns in species co-occurrence as a function of mussels with a

136 checkerboard score (c-score) analysis using the oecosimu function (Vegan package) with the

137 'quasiswap' method (99 simulations) for null model construction (Barberán et al., 2012).

138 Because nitrogen metabolism in association with animals was demonstrated in these locales

139 (Pather et al. 2014, Pfister et al. in press), we tested whether taxa known to be involved in 
140 nitrogen metabolic pathways were present using 3 methodologies. We first examined the taxa

141 identified (down to the level of genus) with the Greengenes database and 16S data in each

142 sample. From literature reports, we assigned taxa to one of 4 transformations: nitrification

143 (either ammonia oxidation or nitrite oxidation), anammox, or nitrate reduction via DNRA or

144 denitrification based on genera associated with each metabolism (Table 1), comparing categories

145 in R (version 2.15, www.R-project.org).

146 Our second analysis of potential nitrogen cycling used PICRUSt to predict the percent of

147 sequences associated with nitrogen metabolism in our 16s data (Langille et al., 2013). Briefly, all

148 OTUs not assigned to the Greengenes database were removed from the OTU table (closed

149 reference), abundance was normalized by 16s rRNA read number, and PICRUSt metagenome

150 predictions were calculated (Greengenes May 2013 release). By inferring the gene families

151 present in our 16s data, we compared whether the different living and inert substrates on Tatoosh

152 Island differed in the amount of OTUs associated with nitrogen metabolism or whether inert

153 substrates in tidepools with or without mussels differed in the abundance of taxa related to

154 nitrogen metabolism.

155 The discovery of nitrogen metabolizing taxa with 16S rRNA data require that those taxa are

156 described and identical or analogous sequences are available. In contrast, shotgun metagenomics

157 directly identifies the sequence associated with metabolic function. Two of our samples of $M$.

158 californianus shells were also shotgun pyrosequenced (Pfister et al., 2010), which allowed us to

159 compare nitrogen metabolisms detected with shotgun metagenomics with 16S OTU reads and

160 PICRUSt predictions.. We sequenced the 16S rRNA V4 amplicons using the Illumina platform

161 described above from DNA archived from a previous extraction from Tatoosh Island, where

162 microbial community biofilms associated with mussel shell surfaces were extracted and 
163 metagenomes sequenced using 454 GS-flx pyrosequencing (Pfister et al., 2010). Briefly, 6

164 mussels were collected on 10 April 2008 from 6 tidepools and 6 additional mussels

165 approximately $5 \mathrm{~m}$ apart on an adjacent exposed rocky bench. All shells were immediately

166 cleaned of all soft tissue. Mean shell length was $4.47 \mathrm{~cm}$ and $4.42 \mathrm{~cm}$ for tidepool and bench

167 mussels, respectively. We thus compared the 16S rRNA V4 amplicon Illumina sequences to the

168 shotgun metagenomic pyrosequencing to determine overlaps in key taxa. The two metagenomes

169 from Pfister et al., (2010) were reanalyzed using MG-RAST for all taxonomic matches and using

170 the SEED Subsystems database for nitrogen metabolism with maximum e-value of $\mathrm{e}<10^{-5}$

171 (http://metagenomics.anl.gov/).

172

173

\section{RESULTS}

174 Some distinction exists among microbial assemblages associated with different substrates at

175 Tatoosh Island

176 Between 54,490 and 250,432 sequences per sample were generated for 26 samples from a

177 range of materials including inert surfaces (rock and glass crucible lids) as well as mussel shells

178 and tissues, algal fronds, sea anemones, and the filtered plankton. All samples were rarified to

17950,000 sequences per sample. OTU richness (total diversity) estimates were greatest for inert

180 substrates and the water column, while the lowest richness was associated with mussel gill and

181 siphon tissue (ANOVA, $\mathrm{F}_{7,16}=4.968, \mathrm{p}=0.004$ ). Species richness was highly correlated with other

182 metrics of diversity including chao 1 and phylogenetic diversity ( $\mathrm{r}=0.98$ to $0.99, \mathrm{p}<0.001$ ), as was

183 equitability (or evenness, $\mathrm{r}=0.780, \mathrm{p}<0.001$ ). Alphaproteobacteria, including Rhodobacteraceae

184 and Hyphomonadaceae, dominated the algal Prionitis tissue and the inert substrates, while

185 Gammaproteobacteria, especially Vibrionaceae, dominated mussel gill and siphon tissue (Fig 1). 
186 The communities associated with mussel shells, anemones, and filtered plankton samples were

187 similarly dominated by Gammaproteobacteria. Mussel shells and anemones similarly had many

188 Vibrionaceae OTUs, with shells also harboring Moritellaceae. OTUs in the Psychromonadaceae

189 were prominent in the plankton. Given our use of a $0.7 \mu \mathrm{M}$ filter, the OTU richness may be

190 underestimated if the smallest bacteria were not retained.

191 In addition to differences in alpha diversity, the microbial community composition and

192 structure on different biotic and inert substrates showed differences in beta diversity. First, the

193 same substrates clustered in a PCoA analysis based on weighted UniFrac distances (Fig 2), e.g.

194 rock substrates clustered with the glass crucibles, while mussel gill and siphon tissue clustered

195 together. The filtered plankton samples were highly similar to each other, while the anemone and

196 Prionitis tissues suggest greater differences among individual hosts. Substrate differences were

197 significant with a permuted ANOVA $\left(\mathrm{F}_{5,18}=6.570, \mathrm{p}<0.001\right)$ when we grouped substrates into 6

198 categories (anemone, red alga, plankton, mussel shell, mussel internal tissue, and inert

199 substrates). Analysis of the differences among those 6 categories showed that each differed

200 significantly from one or several others, except for filtered POM, which did not statistically

201 differ from any other group.

202 A second test indicating beta diversity differences among substrates was revealed in an

203 ANOVA on OTU abundance. There were 10 OTUs that differed significantly in abundance

204 (Bonferroni corrected ANOVA, $\mathrm{p}<0.05$, Fig 3) and these distinctions came primarily from their

205 abundance in association with macrobiota. For example, Moritella and Aliivibrio were found on

206 mussel shell and gill tissue, while Cyanobacteria were primarily associated with algal fronds.

207 Further, the beta diversity differences we detected among substrates were a function of the

208 abundance of OTUs among samples. By comparing OTUs shared between substrates in a 
network plot, it was evident that the abundant OTUs that were detected at least 5000 times were

210 generally common to all substrates (Fig 4a). In contrast, when we examined shared diversity

211 among rare OTUs (those detected only 5 to 10 times across the dataset, Fig $4 \mathrm{~b}$ ), there was strong

212 differentiation among substrates, indicating that the rare OTUs were responsible for the majority

213 of the compositional differences between the microbial communities associated with different

214 substrates.

216 The presence of mussels has little impact on microbial assemblages in tide pools at Second

\section{Beach}

218 In experiments performed at Second Beach, the biogeochemical parameters of tidepools were

219 affected by the presence or absence of mussels (Supplementary Table S1). A principal

220 components analysis that included the ammonium regeneration and removal rates (Pather et al.,

221 2014), the maximum seawater $\mathrm{pH}$ and dissolved oxygen, ammonium, nitrate, nitrite and

222 phosphorus measured in the tidepools over both daytime and nighttime low tides indicated that

223 the first principal component explained $81.7 \%$ of the variance and differed among mussel versus

224 no mussel tidepools ( $\mathrm{p}=0.049$, Supplementary Figure $\mathrm{S} 1$ ). Rock had more than twice the

225 microbial diversity of coverslips (Rock $=3,727$ OTUs, Coverslips $=1,750$ OTUs; $F_{1,18}=140.59$,

$226 \mathrm{p}<0.001)$, perhaps reflecting greater time in the environment. Both types of substrata maintained

227 more diverse and equitable community profiles in tidepools where mussels were removed, than

228 in those with mussels present (Rock=3,282 OTUs, Coverslips=1,343 OTUs; Fig 1b, Two-way

229 ANOVA, $\mathrm{F}_{1,18}=12.759, \mathrm{p}=0.002$ ). However, there was no interaction between substrate and

230 mussel presence $\left(\mathrm{F}_{1,18}=0.013, \mathrm{p}=0.909\right)$, indicating that the distinction between microbial

231 communities associated with natural rock and glass coverslip communities did not depend upon 
232 the presence of mussels. The equitability with which diversity was distributed was strongly

233 correlated with total diversity $(\mathrm{r}=0.920, \mathrm{p}<0.001)$, indicating that when mussels are removed, the

234 equitability of taxa also increases. Further, the microbial communities associated with the rock

235 substrate in tidepools at Second Beach were similar in OTU composition with rock substrate at

236 Tatoosh Island (Fig 1a vs 1b).

237 A high degree of OTU sharing and community structure similarity were observed between

238 microbial communities associated with rock surface or coverslip samples regardless of whether

239 mussels were present (Figs 5 and 6); this was supported by the absence of OTUs with

240 significantly different relative abundances between tidepools with or without mussels based on

241 Bonferroni-corrected ANOVAs. However, there were fewer shared OTUs among rock samples

242 when OTUs that were rare were considered against OTUs that were common (26.7\% versus

$24396.9 \%$ shared). There was no relationship in the degree of OTU sharing with mussel presence or

244 absence. Indeed, in contrast to our comparison of Tatoosh Island substrates, both rock and

245 coverslip samples showed no differentiation between common or rare OTUs as a function of

246 mussels, and the clustering of nodes was highly similar. Further, the presence of mussels was not

247 associated with any changes in the relative weight of deterministic and stochastic forces

248 governing community assembly. OTU co-occurrence was significantly non-random on rock

249 surfaces (c-score analysis; $p<0.01$ ), and this pattern did not change with mussels.

251 Patterns in the distribution of a subset of taxa involved in nitrogen metabolism do show

252 responses to the presence of mussels in tide pools on Second Beach.

253 Nitrifying taxa were at low incidence throughout our samples, while taxa related to nitrate

254 reduction were found in almost every sample (Table 2). Filtered plankton had the highest 
255 incidence of nitrifying OTUs as a result of the genus Paracoccus. The relatively high incidence

256 of denitrifying taxa in the anemone Anthopleura was primarily driven by matches in the

257 Camplyobacteraceae, the group including Campylobacter, a taxon that harbors $n r f$ genes

258 (Pittman and Kelly, 2005). Although most samples also had genera in the Planctomycetes, only

259 some are known to perform anammox (Fuerst and Sagulenko, 2011), and these genera were

260 either absent from our samples or characterized as "other Planctomycetes". We tallied these

261 OTUs for Table 2, but did not perform statistical analyses and interpret these with caution.

262 OTUs associated with nitrogen metabolism, as inferred from PICRUSt, were found across all

263 Tatoosh substrates (Table 2).

264 The percentage of taxa associated with nitrogen transformations and residing on mussel

265 shells was compared between the 16s rRNA amplicon data and existing shotgun metagenomic

266 data (Pfister et al., 2010). The metagenomic data revealed a greater proportion of nitrogen

267 metabolizing taxa, including taxa that were not observed in the amplicon data (Table 2). An

268 analysis of SEED Subsystem functions for the two mussel shell metagenomes yielded estimates

269 of $1.4 \%$ and $1.3 \%$ of the 68,676 and 63,950 proteins with functions known to be related to

270 nitrogen metabolism that were discovered in each sample. The PICRUSt analysis, which

271 inferred functional gene presence, indicated that $0.83 \%$ of the OTUs discovered were related to

272 nitrogen function (Table 2), a value closer to the metagenome discovery rate than our discovery

273 analyzing only the taxa in Table 1 with $16 \mathrm{~S}$ rRNA data, and likely larger due to the inclusion of

274 many nitrogen-metabolizing taxa in addition to those in Table 1.

275 When we compared the presence of OTUs with taxa associated with certain nitrogen

276 metabolisms (e.g. Table 1) in our experimental tidepools, we found that the presence of mussels

277 increased the incidence of putative nitrate reducing taxa on rock substrate, but mussels had no 
278 effect on putative nitrifiers (Table 3). The nitrogen metabolisms on inert substrates that were

279 inferred through PICRUSt also did not differ between tidepools with or without mussels (Table

280 3). The maximum dissolved inorganic nitrogen in each tidepool did not correlate with the

281 observed diversity $(\mathrm{r}=-0.318, \mathrm{p}=0.371)$. Over all 46 samples from Tatoosh and Second Beach

282 that we analyzed, the discovery rate of OTUs with known nitrogen transformations (Table 1) was

283 unrelated to the observed diversity $(\mathrm{r}=-0.127, \mathrm{p}=0.399, \mathrm{n}=46)$. differences in colonization preference, temporal dynamics, the duration in the environment to accrue microbes, and host-specific interactions on the longer-lived macrobiota. The red alga, the anemone and the mussels are all long-lived and could have been present for years prior to our 291 sampling and had ample time to accumulate a microbial assemblage. The clonal nature of the 292 anemone Anthopleura elegantissima might even provide nearly immortal tissue for microbial 293 proliferation. Relatively high diversity on rocks and crucible lids may indicate a number of 294 micro-niches, perhaps as a result of surface irregularities on these substrates. The biotic 295 substrates we sampled are especially likely to have a number of microbial niches, including 296 microtopography and strong oxygen gradients (Heisterkamp et al. 2013).

297 Similarities between the filtered plankton and the animal tissue may have resulted from 298 mussel and anemone tissue harboring planktonic microbiota, due to their feeding activities.

299 Although increased sample size will be needed to quantify the extent of within-host

300 heterogeneity, the animals we examined were dominated by Gammaproteobacteria, including the 
301 symbiont-bearing anemone. In contrast, coral reef invertebrates with eukaryotic photosynthetic

302 symbionts are have been shown to be dominated by Alphaproteobacteria (e.g. Bourne et al.,

303 2013), suggesting differential colonization drivers in different symbiont-bearing invertebrates.

304 Nevertheless, many specialized symbionts of marine bivalves fall within the

305 Gammaproteobacteria (Stewart and Cavenaugh, 2006; Newton et al., 2008).

306 The great similarity in microbial community structure on inert substrates in tidepools

307 regardless of the presence or absence of mussels (Figure 1b, 3, 5, 6), suggests that the enhanced

308 nitrogen regeneration and uptake that has been demonstrated with mussels (Pather et al., 2014)

309 could be due to the microbes on the mussels themselves. The only important functional

310 difference that we found was a greater incidence of nitrate reducing taxa on rocks in the presence

311 of mussels (Table 3), a result likely explained by the ability of mussels to temporarily reduce

312 oxygen levels to the point where reducing processes are favored. OTUs associated with

313 nitrification did not differ. Although mussel presence was associated with a decreased alpha

314 diversity on inert substrates (Fig 1), this did not lead to significant differences in the network of

315 OTUs that were shared across tidepools with and without mussels and thus did not affect beta

316 diversity (Fig 6). Hence, the macrobiota did not drive any shifts in community structure on

317 nearby inert substrates, even though tissue-associated microbial communities were significantly

318 differentiated. Both 16S rRNA and shotgun metagenomic analyses (Table 2) suggest that

319 macrobiota host OTUs that are important for nitrogen cycling. This corroborates work by Welsh

320 and Castadelli (2004) that showed nitrogen metabolism was hosted within a related mussel

321 species. Similarly, deep-sea mussels are known to host nitrogen-utilizing symbionts (Lee and

322 Childress, 1995). In contrast with the shell surface microbes, those with mussel gill and siphon

323 were less diverse (Fig 1). Thus, the elevated nitrite concentrations in tidepools with mussels, 
324 suggesting increased nitrification (Pfister, 2007), may be the result of a direct effect of habitat

325 provisioning for microbes by the macrobiota, rather than simply a microbial community shift on

326 other substrates due to nutrient provisioning. Alternatively, the nitrogen increase due to mussels

327 may not be enough to drive microbial community differences. Indeed, neither microbial

328 community composition nor the expression of several functional genes in coastal sediments

329 showed major changes in response to nutrient perturbations (Bowen et al., 2011). Thus, further

330 exploration of macrobiota as the repository of microbial function, not just as providers of

331 nutrient resources, is warranted.

332 We note that nitrogen-transforming taxa were found with a higher incidence in the

333 metagenomic data than the 16S rRNA V4 amplicon sequencing of mussel shells. Although there

334 are technical differences between the two sequencing methodologies that could lead to detection

335 differences, such as GC bias (Ross et al., 2013), metagenomic data directly identify genes for

336 nitrogen transformations that are relatively conserved and identifiable (independent of host

337 phylogeny), even if the taxa hosting these genes are uncharacterized. Many of the taxa identified

338 in the amplicon survey are not closely related to cultured isolates, and their N-cycling status is

339 unknown. Although this limits our ability to infer function from phylogeny, it nevertheless is an

340 analysis that may become increasingly insightful as our knowledge of sequence-based diversity

341 increases. While we recognize that OTU analysis using $16 \mathrm{~S}$ rRNA data predictions may not yet

342 be the strongest lens to detect function, the increased characterization of taxa involved in

343 nitrogen metabolisms (Ward et al. 2011, Munn 2011), and the analyses of 16S data with

344 PICRUSt (Table 2) suggests that functional inference is possible.

345 Marine microbial community structure has been shown to be composed of a multitude of rare 346 taxa that have deep phylogenetic differences; the extent to which this 'rare biosphere' (Sogin et 
347 al., 2006) drives community function is unknown, though deep sequencing efforts have revealed

348 that there could be the equivalent of a 'seed bank' of rare taxa that are persistent with only

349 relative abundance changing through time and space (Lennon and Jones, 2011; Caporaso et al.,

350 2012; Gibbons et al., 2013). In some ecosystems, rare taxa have also been shown to be as

351 metabolically active as common species (Hamasaki et al., 2007), suggesting that rarity does not

352 preclude functional importance. Although seawater and rock had the highest OTU diversity, the

353 differences among filtered plankton and inert substrates versus biogenic substrates (mussels,

354 seaweed, anemone) sampled in situ demonstrated that macrobiota enhance beta diversity by

355 hosting unique OTUs (Fig 3, Fig 4b), presumably via the provisioning of unique habitats or

356 resources. It is possible that particular microbial taxa end up in association only with intertidal

357 macrobiota, though the selectivity of these associations requires further temporal and spatial

358 sampling. Our results with these benthic macrobiota are, however, in direct contrast to analyses

359 of seawater where the patterns of beta diversity did not differ among abundant and rare taxa

360 (Amaral-Zettler et al., 2010).

361 The demonstration that macrobiota host a unique microbial community compared to the

362 water around them is supported by this study and other recent work with tadpoles (McKenzie et

363 al., 2012) and marine algae (Michelou et al., 2013). Although it has been recognized for several

364 decades that benthic invertebrates in deep sea environments host unique taxa, it may be that

365 benthic macrobiota common to large parts of the ocean are also repositories for unique

366 microorganisms (Grossart et al., 2005; Lee et al., 2011; Bengtsson et al., 2012; Jackson et al.,

367 2012) and loci for important biogeochemistry (Martinez-Garcia et al., 2008; Heisterkamp et al.,

368 2013). The rocky intertidal flora and fauna, though relatively well-understood in terms of the

369 interactions among macrobiota, likely also interact and mediate productivity via a rich microbial 
370 community that we are just beginning to describe. These intertidal macrobiota may also harbor a

371 unique set of taxa adapted to host-associated niches, thereby promoting microbial community

372 diversity in the coastal ocean.

373

374

ACKNOWLEDGEMENTS

376 S. Owens provided expertise in the lab, and G. Caporaso and J. Stombaugh provided critical

377 code. We thank A. Olson for help in the field, O. Moulton for lab assistance, and M. Coleman

378 for comments on the ms. We are grateful to the Makah Tribal Council for access to their lands.

\section{REFERENCES}

381 Amaral-Zettler L, Artigas LP, Baross J, Loka Bharathi PA, Boetius A, Chandramohan D, Herndl J, Sogin M. 2010. A Global Census of Marine Microbes. In: McIntyre, A (ed). Life in the World's Oceans: Diversity, Distribution, and Abundance. Blackwell Publishing: London. pp 223-245.

Barber RT, Smith RL. 1981. Coastal upwelling ecosystems. In: A. Longhurst (Ed.), Analysis of Marine Ecosystems, Academic Press: New York, pp. 31-68.

Barberán A, Bates ST, Casamayor EO, Fierer N. 2012. Using network analysis to explore cooccurrence patterns in soil microbial communities. International Society for Microbial Ecology Journal 6: 343-351 
391 Bengtsson MM, Sjøtun K, Lanzén A, Øvreås L. 2012. Bacterial diversity in relation to secondary 392 production and succession on surfaces of the kelp Laminaria hyperborea. International 393 Society for Microbial Ecology Journal 7: 1452-1458.

394 Bergschneider, H. and Muller-Parker, G. 2008. Nutritional role of two algal symbionts in the 395 temperate sea anemone Anthopleura elegantissima brandt. Biological Bulletin 215: 73-88.

396 Bertagnolli A.D., Treusch A.H., Mason O.U., Stingl U., Vergin K.L., Chan F. 2011. Bacterial 397 diversity in the bottom boundary layer of the inner continental shelf of Oregon, USA. $398 \quad$ Aquatic Microbial Ecology 64: 15-25.

399 Bourne D.G., Dennis P.G., Uthicke S, Soo R.M., Tyson G.W., Webster N. 2013. Coral reef 400 invertebrate microbiomes correlate with the presence of photosymbionts. International $401 \quad$ Society for Microbial Ecology Journal 7: 1452-1458.

402

403

404

405

406

407
Bowen, J.L., Ward B.B., Morrison H.G., Hobbie J.E., Valiela I., Deegan L.A., Sogin M.L. 2011. Microbial community composition in sediments resists perturbation by nutrient enrichment. International Society for Microbial Ecology Journal 5: 1540-1548

Caporaso J.G., Kuczynski J., Stombaugh J., Bittinger K., Bushman F.D., Costello E.K., Fierer N, Gonzalez Peña A, Goodrich JK, Gordon JI, Huttley GA, Kelley ST, Knights D, Koenig JE, Ley RE, Lozupone CA, McDonald D, Muegge BD, Pirrung M, Reeder M, Reeder J, Sevinsky JR, Turnbaugh PJ, Walters WA, Widmann J, Yatsunenko T, Zaneveld J, Knight R. 2010. QIIME allows analysis of high-throughput community sequencing data. Nature Methods 7:335-336. 
411 Caporaso J.G., Bittinger K., Bushman F.D., DeSantis T.Z., Andersen G.L., Knight R. 2010.

412 PyNAST: a flexible tool for aligning sequences to a template alignment. Bioinformatics 26:

$413 \quad 266-7$.

414 Caporaso J.G., Paszkiewicz K., Field D., Knight R., Gilbert J.A. 2012. The Western English

415 Channel contains a persistent microbial seed bank. International Society for Microbial

$416 \quad$ Ecology Journal 6:1089-1093.

417 DeChaine E.G., Cavanaugh C.M. 2006 Symbioses of Methanotrophs and Deep-Sea Mussels

418 (Mytilidae: Bathymodiolinae). In: Overmann, J (ed). Molecular Basis of Symbiosis. Progress

419 in Molecular and Subcellular Biology. Volume 41: 227-249. Springer.

420 Estes, J.A., Duggins, D.O. 1995. Sea otters and kelp forests in Alaska: generality and variation in 421 a community ecological paradigm. Ecological Monographs 65: 75-100.

422 Fan, L., Liu, M., Simister, R., Webster, N.S., and Thomas, T. 2013. Marine microbial symbiosis 423 heats up: the phylogenetic and functional response of a sponge holobiont to thermal stress. 424 International Society for Microbial Ecology Journal 7: 991-1002.

425 Fuerst, J.A., Sagulenko, E. 2011. Beyond the bacterium: Planctomycetes challenge our concepts 426 of microbial structure and function. Nature Reviews Microbiology 9: 403-413.

427 Gibbons, S.M., Caporaso, J.G., Pirrung, M., Field, D., Knight, R., Gilbert J.A. 2013. Evidence

428 for a persistent microbial seed bank throughout the global ocean. Proceedings of the National 429 Academy of Sciences, USA 110:4651-4655. 
430 Gilbert, J.A., Steele, J.A., Caporaso, J.G., Steinbrück, L., Reeder, J., Temperton, B., Huse S,

431 McHardy AC, Knight R, Joint I, Somerfield P, Fuhrman JA, Field D. 2012. Defining

432 seasonal marine microbial community dynamics. International Society for Microbial Ecology

433 Journal 6: 298-308.

434 Grossart, H.-P., Levold, F., Allgaier, M., Simon, M., and Brinkhoff, T. 2005. Marine diatom 435 species harbour distinct bacterial communities. Environmental Microbiology 7: 860-873.

436 Hamasaki, K, Taniguchi, A, Tada Y, Long, R. A., Azam, F. 2007. Actively growing bacteria in

437 the inland Sea of Japan, identified by combined bromodeoxyuridine immunocapture and 438 denaturing gradient gel electrophoresis. Applied Environmental Microbiology 73: 27874392798.

440

441

442

443

444

445

446

447

448

449

450

Heisterkamp, I.M., Schramm, A., Larsen, L.H., Svenningsen, N.B., Lavik, G., de Beer, D., Stief, P. 2013. Shell biofilm-associated nitrous oxide production in marine molluscs: processes, precursors and relative importance. Environmental Microbiology 15:1943-55.

Jackson, S.A., Kennedy, J., Morrissey, J.P., O'Gara, F., Dobson, A.D. 2012. Pyrosequencing reveals diverse and distinct sponge-specific microbial communities in sponges from a single geographical location in Irish waters. Microbial Ecology 64: 105-16.

Kvennefors, E.C.E., Sampayo, E., Kerr, C., Vieira, G., Roff, G., Barnes, A.C. 2012. Regulation of bacterial communities through antimicrobial activity by the coral holobiont. Microbial Ecology. 63: 605-618.

Langille, M.G.I., Zaneveld, J., Caporaso, J.G., McDonald, D., Knights, D., Reyes JA, Clemente JC, Burkepile DE, Vega Thurber RL, Knight R, Beiko RG, Huttenhower C. 2013. Predictive 
functional profiling of microbial communities using 16S rRNA marker gene sequences. Nature Biotechnology 31: 814-821.

453 Lee, O.O., Wang, Y., Yang, J., Lafi, F.F., Al-Suwailem, A., Qian, P.Y. 2011. Pyrosequencing

454 reveals highly diverse and species-specific microbial communities in sponges from the Red 455 Sea. International Society for Microbial Ecology Journal 5: 650-64.

456 Lee, R.W., Childress, J.J. 1995. Assimilation of inorganic nitrogen by seep mytilid 1a, an

457 undescribed deep-sea mussel containing methanotrophic endosymbionts: fate of assimilated

458 nitrogen and the relation between methane and nitrogen assimilation. Marine Ecology

459 Progress Series 123: 137-148.

460 Lennon, J.T., Jones, S.E. 2011. Microbial seed banks: the ecological and evolutionary

461 implications of dormancy. Nature Reviews Microbiology 9: 119-130.

462 Lozupone, C., Lladser, M.E., Knights, D., Stombaugh, J., Knight, R. 2011. UniFrac: an effective 463 distance metric for microbial community comparison. International Society for Microbial 464 Ecology Journal 5: 169-172.

465 Martínez-García, M., Stief, P., Díaz-Valdés, M., Wanner, G., Ramos-Esplá, A., Dubilier, N., 466 Anton J. 2008. Ammonia-oxidizing Crenarchaeota and nitrification inside the tissue of a 467 colonial ascidian. Environmental Microbiology 10: 2991-3001.

468 McDonald, D., Price, M.N., Goodrich, J., Nawrocki, E.P., DeSantis, T.Z., Probst, A., Anderson 469 GL, Knight RL, Hugenholtz P. 2012. An improved Greengenes taxonomy with explicit ranks 470 for ecological and evolutionary analyses of bacteria and archaea. International Society for $471 \quad$ Microbial Ecology Journal 6: 610-618. 
472 McKenzie, V.J., Bowers R., Fierer N., Knight R., Lauber C.L. 2012. Co-habitating amphibian 473 species harbor unique skin bacterial communities in wild populations. International Society $474 \quad$ for Microbial Ecology Journal 6: 588-596. doi: 10.1038/ismej.2011.129.

475 Meyer, F., Paarmann, D., D’Souza, M., Olson, R., Glass, E.M., Kubal, M., Paczian T, Rodriguez 476 A, Stevens R, Wilke A, Wilkening J, Edwards RA. 2008. The metagenomics RAST server 477 a public resource for the automatic phylogenetic and functional analysis of metagenomes. $478 \quad$ BMC Bioinformatics 9: 386.

479 Michelou, V.K., Caporaso, J.G., Knight, R., Palumbi, S.R. 2013. The ecology of microbial 480 communities associated with Macrocystis pyrifera. PLoS One 2013 Jun 19;8(6):e67480

481 Newton, I.L., Girguis, P.R., Cavanaugh, C.M. 2008. Comparative genomics of vesicomyid clam 482 (Bivalvia: Mollusca) chemosynthetic symbionts. BMC Genomics 9: 585. doi: 10.1186/1471$483 \quad 2164-9-585$.

484 Miranda, L.N., Hutchison, K., Grossman, A.R., and Brawley, S.H. 2013. Diversity and 485 abundance of the bacterial community of the red macroalga Porphyra umbilicalis: Did 486 bacterial farmers produce macroalgae? PLOS ONE 8: e58269.

487 Munn, C. 2011. Marine Microbiology: Ecology and Applications, $2^{\text {nd }}$ Edition. Garland Science, $488 \quad$ New York, NY, USA.

489 Paine, R.T. 1966. Food web complexity and species diversity. American Naturalist 100: 65-75.

490 Pather, S., Pfister, C.A., Post, D.A., Altabet, M.A. 2014. Ammonium cycling in the rocky 491 intertidal: remineralization, removal and retention. Limnology Oceanography 59: 361-372.

492 Pfister, C.A. 2007. Tidepool mussels locally increase nutrients and algal growth. Ecology 88: $493 \quad 1647-1653$. 
494 Pfister, C.A., Wootton, J.T., Neufeld, C. 2007. The relative roles of coastal and oceanic

495 processes in determining physical and chemical characteristics of an intensively sampled

496 nearshore system. Limnology Oceanography 52: 1767-1775.

497 Pfister, C.A., Meyer, F., Antonopoulos, D.A. 2010 Metagenomic profiling of a microbial

498 assemblage associated with the California mussel, Mytilus californianus: a node in networks

499 of carbon and nitrogen cycling. PLoS ONE 5(5): e10518. doi:10.1371/journal.pone.0010518.

500 Pittman, M.S., Kelly D.J. 2005. Electron transport through nitrate and nitrite reductases in

$501 \quad$ Campylobacter jejuni. Biochemical Society Transactions 33: 190-2.

502 Price, M.N., Dehal P.S., Arkin A.P. 2009. FastTree: Computing Large Minimum-Evolution

503 Trees with Profiles instead of a Distance Matrix. Molecular Biology and Evolution 26: 1641-

$504 \quad 1650$.

505 Qian, P.Y., Dobretsov, S., Dahms, H.U., and Pawlik, J. 2006. Antifouling activity and microbial

506 diversity of two congeneric sponges Callyspongia spp. from Hong Kong and the Bahamas.

507 Marine Ecology Progress Series 324: 151-165.

508 Ramette, A. 2007. Multivariate analyses in microbial ecology. FEMS Microbiol Ecology 62:

$509 \quad 142-160$.

510 Ross, M.G., Russ C., Costello M., Hollinger A., Lennon N.J., Hegarty R., Nusbaum C, Jaffe DB.

511 2013. Characterizing and measuring bias in sequence data. Genome Biology 14:R51.

512 doi:10.1186/gb-2013-14-5-r51

513 Secord, D. and Augustine, L. 2000 Biogeography and microhabitat variation in temperate algal-

514 invertebrate symbioses: zooxanthellae and zoochlorellae in two Pacific intertidal sea

515 anemones, Anthopleura elegantissima and A. xanthogrammica. Invertebrate Biology 119:

Pfister, Gilbert, Gibbons, p. 23 
517 Sogin, M.L., Morrison, H.G., Huber, J.A., Mark Welsh, D., Huse, S.M., Neal, P.R., Arrieta JM, 518 Herndl GJ. 2006 Microbial diversity in the deep sea and the underexplored "rare biosphere". 519 Proceedings of the National Academy of Science, USA 103: 12115-12120.

520 Stahl, D.A., Lane, D.J., Olsen, G.J., Pace, N.R. 1984. Analysis of hydrothermal vent-associated 521 symbionts by ribosomal RNA sequences. Science 224: 409-411.

522 Stewart, F.J., Cavanaugh C.M. 2006 Symbiosis of thioautotrophic bacteria with Riftia 523 pachyptila. Progress in Molecular and Subcellular Biology. 41: 197-225.

524 Taylor, M.W., Radax, R., Steger, D., and Wagner, M. 2007. Sponge-Associated microorganisms: evolution, ecology, and biotechnological Potential. Microbiology and Molecular Biology Reviews 71: 295-347.

Telford, R.J., Vandvik, V., Birks, H.J. 2006. Dispersal limitations matter for microbial morphospecies. Science 312: 1015.

Ward, B.B., D. J. Arp, M. J. Klotz, eds. 2011. Nitrification. John Wiley and Sons, Hoboken, NJ, USA.

Webster, N.S. and Taylor, M.W. 2012. Marine sponges and their microbial symbionts: love and other relationships. Enviromental Microbiology 14: 335-346.

533 Wegner, K.M., Volkenborn, N., Peter, H., and Eiler, A. 2013. Disturbance induced decoupling

534 between host genetics and composition of the associated microbiome. BMC Microbiology 13: 252. 
536 Welsh, D.T, Castaldelli, G. 2004. Bacterial nitrification activity directly associated with isolated 537 benthic marine animals. Marine Biology 144: 1029-1037.

538 Wootton, J.T. 1994. Predicting direct and indirect effects: An integrated approach using 539 experiments and path analysis. Ecology 75: 151-165.

540 Zurel, D., Benayahu, Y., Or, A., Kovacs, A., and Gophna, U. 2011. Composition and dynamics 541 of the gill microbiota of an invasive Indo-Pacific oyster in the eastern Mediterranean Sea.

542 Environmental Microbiology 13: 1467-1476. 
547 Figure 1. The proportional representation of OTUs among the major microbial groups (colored 548 bars), with the overall mean observed OTU richness (+SE) among all substrate types at a.

549 Tatoosh Island, and b. in tidepools where natural rock substrate and coverslips were sampled in 550 the context of an experimental removal of mussels. The substrates in Fig la showed significant 551 differences in observed richness (ANOVA, $\left.\mathrm{F}_{7,16}=4.968, \mathrm{p}=0.004\right)$ with rocks $(\mathrm{n}=3)$, crucible lids $552(n=9)$ and filtered plankton $(n=3)$ showing the greatest richness while the lowest observed 553 richness was associated with mussel gill $(n=3)$ and siphon $(n=1)$ tissue. OTU richness of mussel 554 shell $(\mathrm{n}=2)$, anemone $(\mathrm{n}=2)$, and red algae $(\mathrm{n}=2)$ was intermediate to the others. In $\mathrm{b}$. Tidepools 555 with mussels removed had greater OTU richness than those with mussels (Two-Way ANOVA, $\left.556 \mathrm{~F}_{1,18}=12.759, \mathrm{p}=0.002\right)$ while rock had over twice the OTU richness of coverslips $\left(\mathrm{F}_{1,18}=140.59\right.$, $557 \mathrm{p}<0.001)$; there was no interaction between substrate and mussel presence.

559 Figure 2. A PCoA of the OTU beta diversity of substrates on Tatoosh Island, demonstrating the 560 clustering among the different microbial assemblages associated with each substrate. The 561 weighted UniFrac metric was used to incorporate relative abundance; the first axis explained $56240.2 \%$ of the variance, while the second explained $14.8 \%$. Differences among substrates were 563 significant (PERMANOVA, $\mathrm{F}_{5,18}=6.570, \mathrm{p}<0.001$ ), and groupings that included anemone,

564 Prionitis, mussel shell, mussel tissue, and inert substrates were differentiated while plankton 565 were indistinguishable from all.

567 Figure 3 . The relative abundance of the 10 OTUs that differed among the Tatoosh Island 568 substrates (Boniferroni-corrected ANOVA, $\mathrm{p}<0.05$ ). 
570 Figure 4. Shared OTU diversity among microbes sampled from the substrate groupings as in Fig

571 1, 2 and 3 at Tatoosh Island and portrayed as a spring-embedded layout, where OTUs that are in

572 common bring nodes or samples together and OTUs that are distinct repel nodes. In a., only

573 common OTUs detected more than 5,000 times are included, while b. shows only rare OTUs that

574 were present 5 to 10 times across the entire dataset.

575

576 Figure 5. A PCoA of the OTU diversity of tidepool rock $(n=10)$ versus coverslip $(n=12)$

577 substrates at Second Beach, demonstrating strong clustering among the microbial assemblages

578 from the two substrates, while the presence of mussels (filled symbols) versus removal of

579 mussels (open symbols) were not a factor for explaining beta diversity. Using weighted UniFrac,

580 the first axis explained $46.5 \%$ of the variance, while the second explained $20.3 \%$.

582 Figure 6. Shared OTU diversity among a. microbes sampled from tidepool rock versus coverslip

583 (lighter green) substrates and b. samples distinguished by whether mussels were present (blue) or 584 absent (red) from tidepools at Second Beach. The spring-embedded layout shows OTUs that are 585 in common bring nodes or samples together and OTUs that are distinct repel nodes. Only 586 common OTUs greater than $>5000$ are included. Analyses of relatively rare OTUs did not 587 change the network pattern. 


\section{Table $\mathbf{1}_{\text {(on next page) }}$}

The genera associated with different microbial nitrogen transformations.

Table 1. The genera associated with different microbial nitrogen transformations that were searched in all samples via the Greengenes database. For nitrification, any taxa associated with ammonium or nitrite oxidation are included, while nitrate reduction includes taxa for denitrification and DNRA. For anammox, we searched for taxa with "Candidatus" status. $\S D$ ue to the abundance and functional diversity of the Vibrio genus and the possibility that many Vibrio species are not involved in nitrate reduction, we did not include Vibrio OTUs in Tables 2 and 3. 
Table 1. The genera associated with different microbial nitrogen transformations that were searched in all samples via the Greengenes database. For nitrification, any taxa associated with ammonium or nitrite oxidation are included, while nitrate reduction includes taxa for denitrification and DNRA. For anammox, we searched for taxa with "Candidatus" status. $\S$ Due to the abundance and functional diversity of the Vibrio genus and the possibility that many Vibrio species are not involved in nitrate reduction, we did not include Vibrio OTUs in Tables 2 and 3.

\begin{tabular}{|c|c|c|}
\hline nitrification & Nitrate reduction & anammox \\
\hline Alcaligenes & Azospirillum & "Candidatus" \\
\hline Nitrobacter & Campylobacter & \\
\hline Nitrococcus & Desulforvibrio & \\
\hline Nitrolancetus & Nitratifractor & \\
\hline Nitrosococcus & Nitratiruptor & \\
\hline Nitrosolobos & Paracoccus & \\
\hline Nitrosomonas & Rhodobacter & \\
\hline Nitrosopumilis & Sulfospirillum & \\
\hline Nitrosovibrio & Wolinella & \\
\hline Nitrospina & Vibrio§ & \\
\hline \multicolumn{3}{|l|}{ Nitrospira } \\
\hline Nitrotoga & & \\
\hline Paracoccus & & \\
\hline
\end{tabular}




\section{Table 2 (on next page)}

The OTUs discovered in each substrate type at Tatoosh Island associated with 3 broad nitrogen transformations.

Table 2. The mean percent of OTUs discovered in each substrate type that is associated with each of the 3 broad nitrogen transformations (taxa listed in Table 1) or overall nitrogen metabolism (PICRUSt) at Tatoosh Island. No "Candidatus" were found in the 16S; the anammox category contains Planctomycetes as an estimate of anammox potential only. Mussel shell samples were analyzed with both the V4 region of the 16S rRNA as well as through shotgun metagenomics. 
Table 2. The mean percent of OTUs discovered in each substrate type that is associated with each of the 3 broad nitrogen transformations (taxa listed in Table 1) or overall nitrogen metabolism (PICRUSt) at Tatoosh Island. No "Candidatus" were found in the 16S; the anammox category contains Planctomycetes as an estimate of anammox potential only. Mussel shell samples were analyzed with both the V4 region of the 16S rRNA as well as through shotgun metagenomics.

\begin{tabular}{|c|c|c|c|c|c|c|c|c|}
\hline \multirow[b]{2}{*}{ Substrate } & \multirow[b]{2}{*}{$\begin{array}{l}\text { Substrate } \\
\text { type }\end{array}$} & \multicolumn{2}{|c|}{ Nitrification } & \multicolumn{2}{|c|}{ Nitrate reduction } & \multicolumn{2}{|c|}{ Anammox } & \multirow{2}{*}{$\begin{array}{l}\text { N metabolism } \\
\text { PICRUSt }\end{array}$} \\
\hline & & $\underline{16 \mathrm{~s}}$ & Meta-genome & $\underline{16 \mathrm{~s}}$ & $\begin{array}{c}\text { Meta- } \\
\text { genome }\end{array}$ & $\underline{16 \mathrm{~s}}$ & $\begin{array}{l}\text { Meta- } \\
\text { genome }\end{array}$ & \\
\hline $\begin{array}{l}\text { Mussel } \\
\text { siphon }\end{array}$ & biogenic & 0.0000 & & 0.0326 & & 0.0008 & & 0.8811 \\
\hline $\begin{array}{l}\text { Mussel } \\
\text { gill }\end{array}$ & biogenic & 0.0000 & & 0.4159 & & 0.0009 & & 0.9295 \\
\hline $\begin{array}{l}\text { Mussel } \\
\text { shell }\end{array}$ & biogenic & 0.0000 & 0.4604 & 0.0049 & 0.9882 & 0.0043 & 0.1711 & 0.8344 \\
\hline filtered plankton & biogenic & 0.0102 & & 0.1851 & & 0.0391 & & 0.7636 \\
\hline $\begin{array}{l}\text { A. elegantissima } \\
\text { (anemone) }\end{array}$ & biogenic & 0.0000 & & 1.8961 & & 0.0804 & & 0.8658 \\
\hline $\begin{array}{l}\text { Prionitis } \\
\text { (red alga) }\end{array}$ & biogenic & 0.0000 & & 0.4278 & & 0.0399 & & 0.6638 \\
\hline rock & inert & 0.0048 & & 0.0551 & & 0.0390 & & 0.7119 \\
\hline crucible lid & artificial & 0.0094 & & 0.2120 & & 0.0218 & & 0.6325 \\
\hline
\end{tabular}


Table 3 (on next page)

OTUs discovered on inert substrates in experimental Second Beach tidepools associated with 3 broad nitrogen transformations.

Table 3. The mean percent of OTUs discovered on inert substrates in experimental Second Beach tidepools that were associated with each of the 3 broad nitrogen transformations (taxa listed in Table 1) or overall nitrogen metabolism (PICRUSt). P-values are listed for t-tests for a significant difference on each substrate as a function of mussel presence. The only significant contrast was the greater incidence of OTUs associated with nitrate reduction on natural rock substrate in tidepools with mussels. 
Table 3. The mean percent of OTUs discovered on inert substrates in experimental Second Beach tidepools that were associated with each of the 3 broad nitrogen transformations (taxa listed in Table 1) or overall nitrogen metabolism (PICRUSt). P-values are listed for t-tests for a significant difference on each substrate as a function of mussel presence. The only significant contrast was the greater incidence of OTUs associated with nitrate reduction on natural rock substrate in tidepools with mussels.

\begin{tabular}{|c|c|c|c|c|c|c|}
\hline Tidepool substrates & \multicolumn{2}{|c|}{ Nitrification } & \multicolumn{2}{|c|}{ Nitrate reduction } & \multicolumn{2}{|c|}{$\mathrm{N}$ metabolism } \\
\hline & $16 s$ & T-test & $16 \mathrm{~s}$ & T-test & PICRUSt & T-test \\
\hline $\begin{array}{l}\text { Natural rock substrate with } \\
\text { mussels }(n=5)\end{array}$ & 0.0001 & $\mathrm{p}=0.284$ & 0.1890 & $\mathrm{p}=0.043 *$ & 0.7433 & $\mathrm{p}=0.952$ \\
\hline $\begin{array}{l}\text { Natural rock substrate without } \\
\text { mussels }(n=5)\end{array}$ & 0.0011 & & 0.0151 & & 0.7422 & \\
\hline Coverslip with mussels $(n=6)$ & 0.0004 & $\mathrm{p}=0.456$ & 0.0737 & $\mathrm{p}=0.471$ & 0.7421 & $\mathrm{p}=0.218$ \\
\hline $\begin{array}{l}\text { Coverslip without mussels } \\
(\mathrm{n}=6)\end{array}$ & 0.0019 & & 0.1785 & & 0.7084 & \\
\hline
\end{tabular}




\section{Figure 1}

The proportional representation of OTUs and the mean observed OTU richness among substrates sampled.

Figure 1. The proportional representation of OTUs among the major microbial groups (colored bars), with the overall mean observed OTU richness (+SE) among all substrate types at a. Tatoosh Island, and b. in tidepools where natural rock substrate and coverslips were sampled in the context of an experimental removal of mussels. The substrates in Fig la showed significant differences in observed richness (ANOVA, $\left.F_{7,16}=4.968, p=0.004\right)$ with rocks $(n=3)$, crucible lids $(n=9)$ and filtered plankton $(n=3)$ showing the greatest richness while the lowest observed richness was associated with mussel gill $(n=3)$ and siphon $(n=1)$ tissue. OTU richness of mussel shell $(n=2)$, anemone $(n=2)$, and red algae $(n=2)$ was intermediate to the others. In b. Tidepools with mussels removed had greater OTU richness than those with mussels (Two-Way ANOVA, $F_{1,18}=12.759, p=0.002$ ) while rock had over twice the OTU richness of coverslips $\left(F_{1,18}=140.59, p<0.001\right)$; there was no interaction between substrate and mussel presence. 


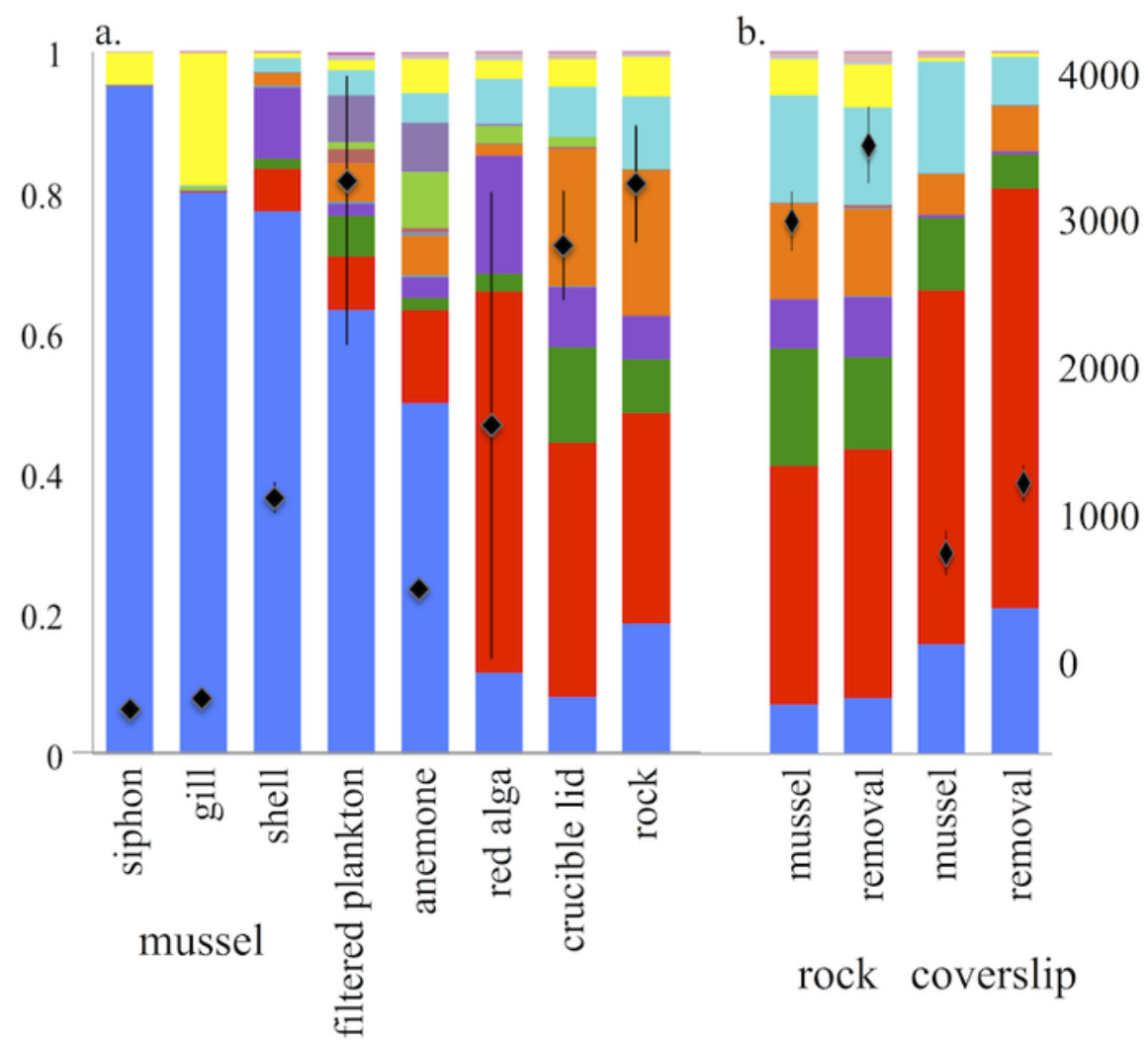

घ other

" Verrucomicrobia

- Planctomycetes

Other Proteobacteria

- other bacterial

- Fusobacteria

Epsilonproteobacteria

- Deltaproteobacteria

- Betaproteobacteria

- Flavobacteria

- Actinobacteria

- Cyanobacteria

- Bacteriodetes

- Alphaproteobacteria

Gammaproteobacteria

rock coverslip 


\section{Figure 2}

A PCOA of the OTU beta diversity of substrates on Tatoosh Island.

Figure 2. A PCOA of the OTU beta diversity of substrates on Tatoosh Island, demonstrating the clustering among the different microbial assemblages associated with each substrate. The weighted UniFrac metric was used to incorporate relative abundance; the first axis explained $40.2 \%$ of the variance, while the second explained $14.8 \%$. Differences among substrates were significant (PERMANOVA, $\mathrm{F}_{5,18}=6.570, \mathrm{p}<0.001$ ), and groupings that included anemone, Prionitis, mussel shell, mussel tissue, and inert substrates were differentiated while plankton were indistinguishable from all.

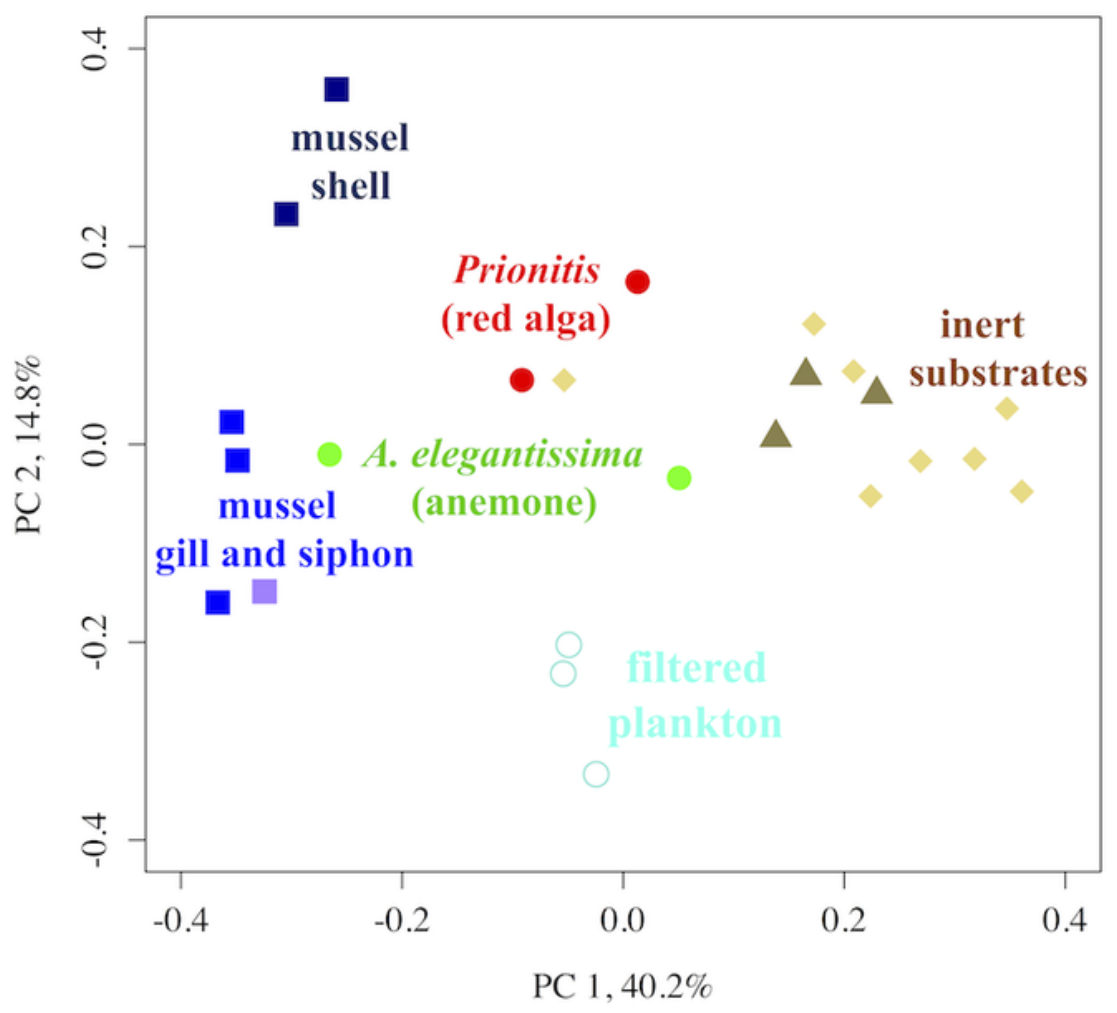


Figure 3

The relative abundance of the 10 OTUs that differed among the Tatoosh Island substrates.

Figure 3. The relative abundance of the 10 OTUs that differed among the Tatoosh Island substrates (Boniferroni-corrected ANOVA, $p<0.05$ ).

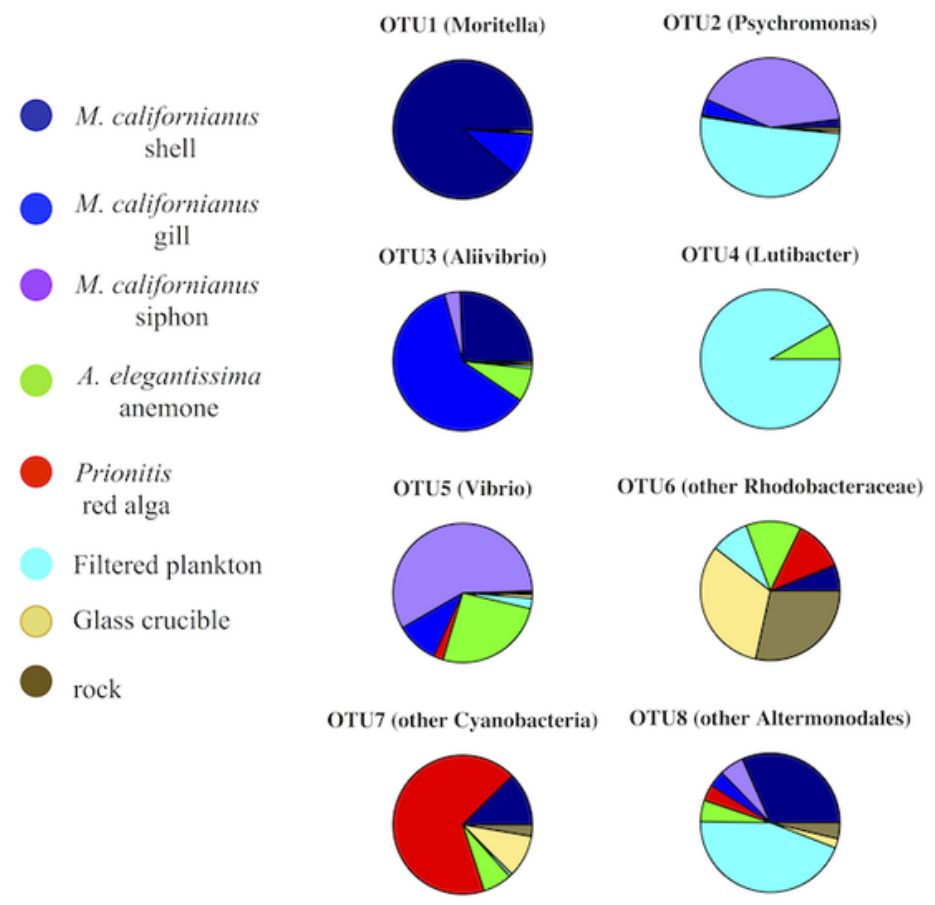

OTU9 (other Clostridiales) OTU10 (other Campylobacterales)
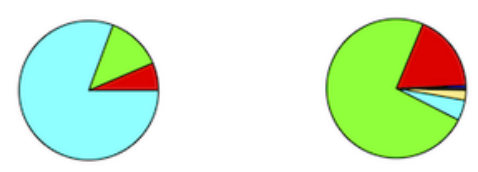


\section{Figure 4}

Shared OTU diversity among microbes sampled from the substrate groupings at Tatoosh Island and portrayed as a spring-embedded layout.

Figure 4. Shared OTU diversity among microbes sampled from the substrate groupings as in Fig 1, 2 and 3 at Tatoosh Island and portrayed as a spring-embedded layout, where OTUs that are in common bring nodes or samples together and OTUs that are distinct repel nodes. In a., only common OTUs detected more than 5,000 times are included, while b. shows only rare OTUs that were present 5 to 10 times across the entire dataset.
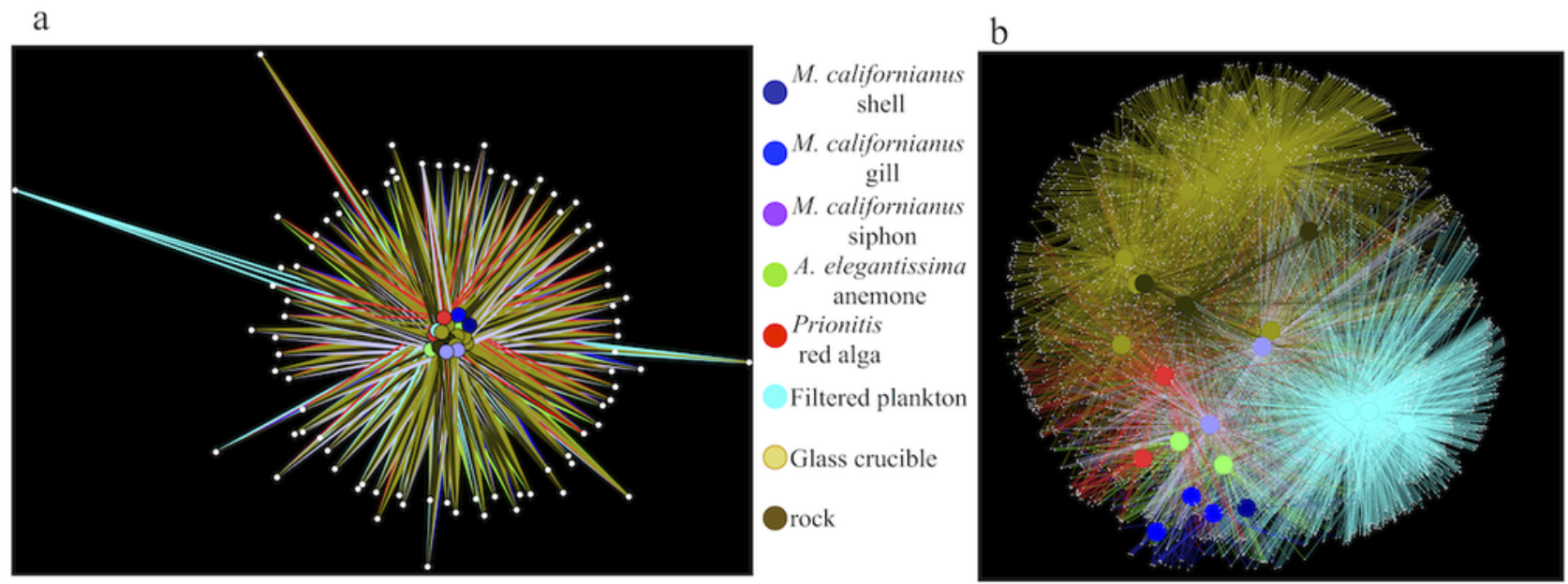


\section{Figure 5}

A PCOA of the OTU diversity of tidepool rock versus coverslip substrates at Second Beach, WA.

Figure 5. A PCoA of the OTU diversity of tidepool rock $(n=10)$ versus coverslip $(n=12)$

substrates at Second Beach, demonstrating strong clustering among the microbial assemblages from the two substrates, while the presence of mussels (filled symbols) versus removal of mussels (open symbols) were not a factor for explaining beta diversity. Using weighted UniFrac, the first axis explained $46.5 \%$ of the variance, while the second explained $20.3 \%$.

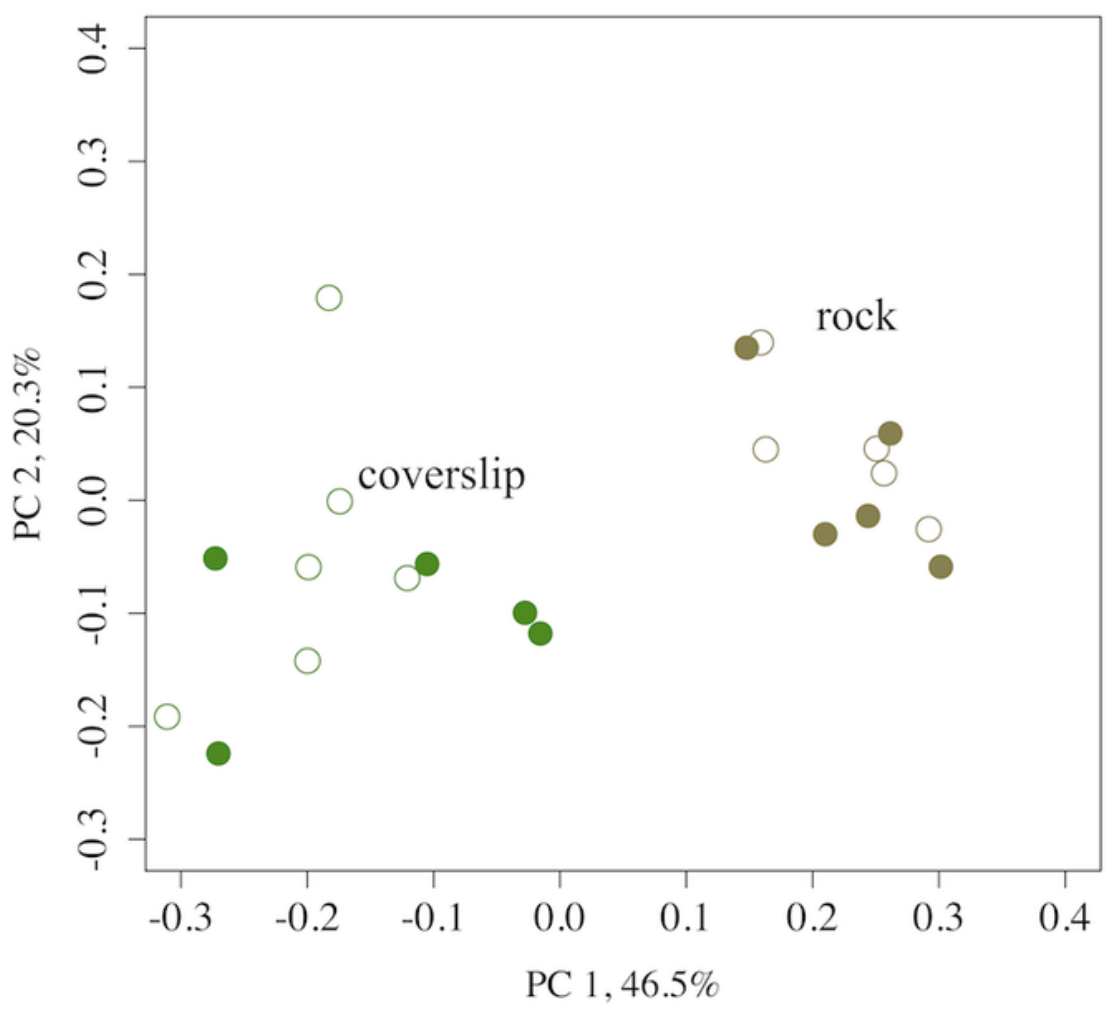




\section{Figure 6}

Shared OTU diversity among microbes sampled from tidepool rock versus coverslip substrates in tidepools at Second Beach, WA.

Figure 6. Shared OTU diversity among a. microbes sampled from tidepool rock versus coverslip (lighter green) substrates and b. samples distinguished by whether mussels were present (blue) or absent (red) from tidepools at Second Beach. The spring-embedded layout shows OTUs that are in common bring nodes or samples together and OTUs that are distinct repel nodes. Only common OTUs greater than $>5000$ are included. Analyses of relatively rare OTUs did not change the network pattern.

a.

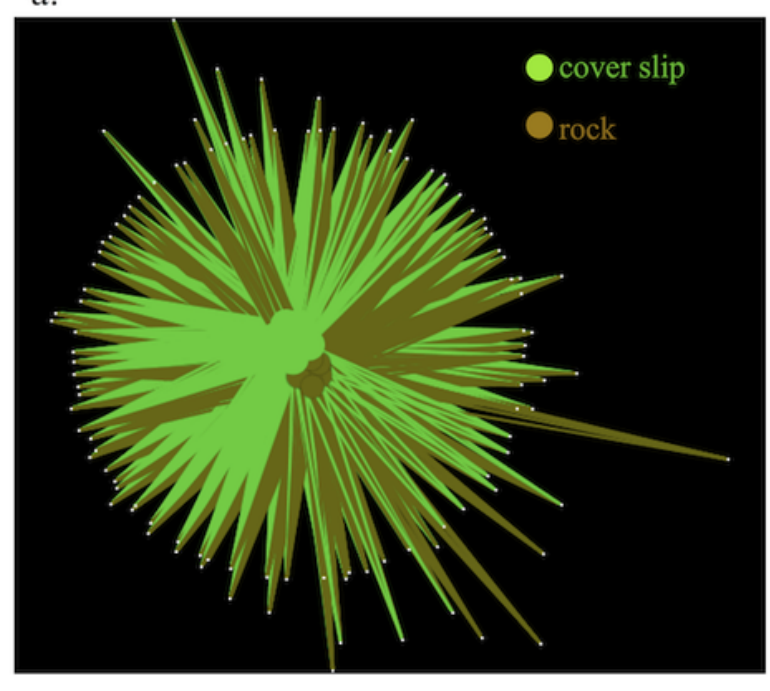

b.

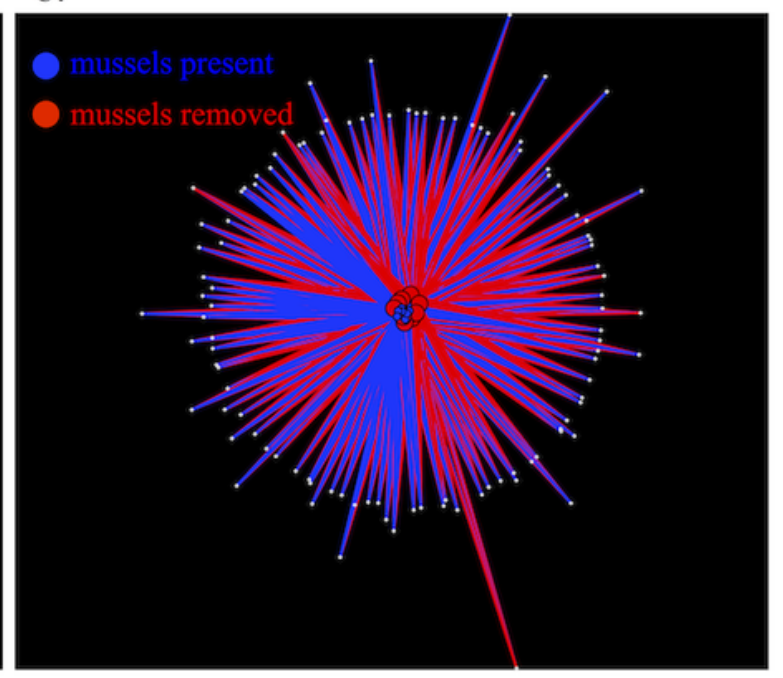

